\title{
PENGARUH UKURAN BENIH TERHADAP PERKECAMBAHAN DAN PERTUMBUHAN BIBIT MINDI (Melia azedarach L.)
}

\author{
The Effect of Seed Size on Germination and Seedling Growth of Mindi \\ (Melia azedarach $L$.) \\ Eliya Suita dan/and Megawati \\ Balai Penelitian Teknologi Perbenihan Bogor \\ Jl. Pakuan, Ciheuleut, Bogor, P.O. Box 105, Telp./Fax : 0251-327768 \\ Naskah masuk : 16 Juni 2008; Naskah diterima : 16 Januari 2009
}

\begin{abstract}
In supporting the planting program, seed procurement in satisfactory qualities and adequate quantity has to be achieved. The problem that often occur is how to select the seeds effectively in order to get ones with high physiology quality and seeds size is one among the related factors. Mindi (Melia azedarach) seeds have varying sizes. It is presumed that big-size seeds will offer physiological advantage, suice then have more than enough nutrition reserve for gemination; and therefore mindi seeds should be examined. Research has been conducted to look into the effect of mindi seed selection based on size and weight on their germination and seedling growth. The observed data were germination capacity (percentage), germination rate, and seed-quality index. Those data were further assessed by a completely randomized design with a single factor. The factor was size/weight of seeds, small/length $<11 \mathrm{~mm}$ and diameter $<6,5 \mathrm{~mm}$ ) (a1), medium (length 11- 14mm and diameter 6,5-8,5 mm) (a2), big (length $>14 \mathrm{~mm}$ and diameter $>8,5 \mathrm{~mm}$ ) (a3), and control (a0). The control was merely the mixture of seeds with varying sizes. It turns out that germination percentages of the control seeds $(70.33 \%)$ and big-size seeds $(73.00 \%)$ were greater than those of medium size $(55.00 \%)$ and small size $(32.67 \%$. Likewise, seed-quality index were consecutively $0.4023 \% \mathrm{KN}$ let mal (for control seeds), $0.4147 \%$ $\mathrm{KN}$ let mal (big-size seeds), and $0.3063 \% \mathrm{KN}$ let mal (for medium-size as well as small-size seeds). Further medium-size seeds exhibited the greatest height growth $(13,98 \mathrm{~cm})$ and differed significantly from other seeds. Meanwhile, big-size and medium size seeds had similar diameter growth (1,84 mm) and are significantly greater than others. These results imply that selection of mindi seeds should focused on medium-size and big-size ones, and keep attentive to empty seeds and preventing from pest and disease attacks.
\end{abstract}

Keywords : Germination, mindi (M. azedarach), seedling growth, seed size/weight

\begin{abstract}
ABSTRAK
Pengadaan benih untuk meningkatkan keberhasilan penanaman memerlukan benih dalam jumlah dan mutu yang baik. Permasalahan yang terkadang muncul dalam rangka pengadaan benih adalah menentukan cara seleksi benih yang memiliki mutu fisiologis yang tinggi, salah satunya berhubungan dengan ukuran benih. Benih mindi (Melia azedarach) mempunyai ukuran bervariasi. Penelitian seleksi benih mindi dilakukan karena adanya dugaan bahwa benih berukuran besar memberikan keuntungan dilihat dari mutu fisiologis kerena persediaan cadangan makanan yang lebih mencukupi untuk perkecambahan. Terkait dengan hal tersebut telah dilakukan penelitian dengan tujuan mengetahui pengaruh seleksi benih berdasarkan ukuran dan berat terhadap perkecambahan dan pertumbuhan bibit
\end{abstract}


mindi. Rancangan percobaan untuk analisa data didekati dengan rancangan acak lengkap, dimana faktor ukuran benih meliputi : a0 = kontrol (benih campuran), a1 = ukuran benih kecil ( panjang $<11 \mathrm{~mm}$ dan diameter $<6,5 \mathrm{~mm}$ ), a2 = ukuran benih sedang ( panjang $11-14 \mathrm{~mm}$ dan diameter $6,5-8,5 \mathrm{~mm}$ ), a3 = ukuran benih besar ( panjang $>14 \mathrm{~mm}$ dan diameter $>8,5 \mathrm{~mm}$ ). Parameter yang diamati adalah daya berkecambah, kecepatan berkecambah dan indeks mutu bibit. Hasil penelitian menunjukkan daya berkecambah benih tanpa perlakuan (kontrol) mempunyai daya berkecambah sebesar 70,33\% dan benih besar $(73.00 \%)$ lebih baik dan berbeda nyata dibandingkan dengan ukuran sedang $(55,00 \%)$ dan kecil (32,67\%), dengan demikian semakin besar ukuran benih maka semakin tinggi daya berkecambahnya. Kecepatan berkecambah tanpa perlakuan (kontrol) mempunyai kecepatan berkecambah sebesar 0,4023 $\% \mathrm{KN} /$ et mal, ukuran besar $(0,4147 \% \mathrm{KN} /$ et mal) dan sedang $(0,3063 \% \mathrm{KN} /$ et mal $)$ memiliki nilai yang hampir sama dan tidak berbeda nyata. Ukuran benih sedang memiliki pertunbuhan tinggi bibit terbesar $(13,98 \mathrm{~cm})$ dan berbeda nyata dengan lainnya, tetapi untuk pertumbuhan diameter, ukuran benih sedang dan besar memiliki nilai yang sama $(1,84 \mathrm{~mm})$ dan berbeda nyata dengan ukuran benih lainnya. Dari penelitian ini disarankan seleksi benih untuk mindi sebaiknya didasarkan pada ukuran benih sedang dan besar, dengan tetap memperhatikan benih hampa dan terkena serangan hama dan penyakit.

\section{Kata kunci : Mindi (M. azedarach), perkecambahan, pertumbuhan bibit, ukuran benih}

\section{PENDAHULUAN}

Mindi (Melia azedarach) termasuk famili Meliaceae, tumbuh tersebar di dataran sedang dan tinggi di Jawa, Bali, Nusa Tenggara Barat dan Nusa Tenggara Timur. Kayunya baik digunakan untuk peti, papan bangunan, panil, vinir hias dan mebel ( Martawijaya et al., 1989)

Untuk menunjang keberhasilan penanaman, pengadaan benih dalam jumlah dan mutu yang memadai sangat dibutuhkan. Permasalahan yang berkaitan dengan pengadaan benih adalah menentukan cara seleksi benih yang efektif untuk memilih benih-benih bermutu fisiologis tinggi. Menurut Schmidt (2002), ukuran benih terkadang berkorelasi dengan viabilitas dan vigor benih, dimana benih yang relatif berat cenderung mempunyai vigor yang lebih baik. Sorensen dan Campbell (1993) menyatakan benih dengan berat dan ukuran lebih besar lebih banyak dipilih karena umumnya berhubungan dengan kecepatan berkecambah dan perkembangan semai yang lebih baik.

Berdasarkan beberapa penelitian, untuk jenis-jenis tertentu benih besar mempunyai kualitas yang lebih baik daripada benih kecil, namun pada jenis tertentu ukuran benih tidak berpengaruh signifikan terhadap viabilitas dan vigor benih (Bonner, 1987). Hendromono (1996) menyatakan bahwa benih Hymenaea courbaril yang berukuran besar menghasilan bibit yang pertumbuhannya lebih cepat daripada benih kecil walaupun diameter pangkal batangnya dan bibit tersebut tidak berbeda nyata, diduga karena benih besar mempunyai embrio dan cadangan makanan yang lebih besar sehingga pertumbuhannya lebih cepat. Sifat ini berlanjut sampai tanaman berumur satu tahun di lapangan. Namun Chaisurisri et al. (1994) tidak menemukan hubungan yang nyata secara statistik antara benih berukuran besar dan kecil dengan pertumbuhan semai Picea sitchensis pada umur 8 bulan.

Benih mindi mempunyai ukuran dan berat bervariasi. Adanya dugaan bahwa benih berukuran besar memberikan keuntungan dilihat dari mutu fisiologis kerena persediaan cadangan makanan yang lebih mencukupi untuk perkecambahan, perlu diteliti untuk jenis ini. Diharapkan adanya klasifikasi ukuran benih ini dapat memperbaiki mutu fisiologis benih yang dapat menjamin perkecambahan dan pertumbuhan bibit lebih baik. Dengan demikian upaya tersebut akan meningkatkan keberhasilan persemaian dalam rangka menyediakan bibit bermutu untuk kegiatan penanaman.

Penelitian ini bertujuan untuk mengetahui pengaruh ukuran benih terhadap perkecambahan dan pertumbuhan bibit mindi. 


\section{BAHAN DAN METODE}

\subsection{Waktu dan Lokasi Penelitian}

Buah mindi diperoleh dari tegakan mindi di daerah Bogor pada bulan Maret 2006. Pengujian mutu benih dilaksanakan di laboratorium Balai Penelitian Teknologi Perbenihan (BPTP) Bogor pada bulan Maret Juni 2006.

\subsection{Bahan dan Peralatan}

Perkecambahan benih mindi (M. azedarach) menggunakan media campuran pasir dan tanah $(1: 1 \mathrm{v} / \mathrm{v})$. Peralatan yang digunakan meliputi bak kecambah, oven, timbangan analitik, kaliper, label, kantong plastik dan lain-lain.

\subsection{Metode Penelitian}

Penelitian ini menggunakan rancangan acak lengkap (RAL) dengan 3 ulangan dan pada tiap ulangan digunakan 50 butir benih. Sebagai perlakuan adalah ukuran benih yaitu :

$\mathrm{a} 0=$ kontrol (campuran/benih dengan berbagai ukuran)

a1 $=$ ukuran benih kecil ( panjang $<11 \mathrm{~mm}$ dan diameter $<6,5 \mathrm{~mm}$ )

a2 = ukuran benih sedang ( panjang $11-14 \mathrm{~mm}$ dan diameter $6,5-8,5 \mathrm{~mm}$ )

a3 $=$ ukuran benih besar ( panjang $>14 \mathrm{~mm}$ dan diameter $>8,5 \mathrm{~mm}$ )

Prosedur penelitian dimulai dengan pengunduhan buah yang sudah masak fisiologis, ditandai dengan warna kulit buah hijau kekuning-kuningan yang diunduh saat masih di pohon. Buah mindi sudah diunduh dimasukkan karung dan dibiarkan (diperam) selama lebih kurang 3 hari kemudian baru diekstraksi dan dikering udarakan.

Pengukuran kadar air benih menggunakan 3 ulangan masing-masing lebih kurang 5 gram, dan penentuan berat 1000 butir menggunakan 8 ulangan masing-masing 100 butir. Rumusan perhitungan penentuan kadar air benih dan berat 1000 butir mengikuti peraturan ISTA (Anonim, 1999).

Benih hasil ekstraksi dipisahkan berdasarkan ukuran yaitu besar, sedang dan kecil. Benih-benih yang sudah dipisahkan sesuai dengan kriteria ukurannya, diretakkan kemudian ditabur/ dikecambahkan pada bak kecambah yang sudah berisi media campuran tanah dan pasir $(1: 1 \mathrm{v} / \mathrm{v})$ dan ditutup plastik. Penyiraman dilakukan setiap hari.

Pengamatan terhadap perkecambahan dilakukan setiap 2 hari dengan mencatat jumlah kecambah normal yang tumbuh. Kriteria kecambah normal adalah telah munculnya sepasang daun pertama.

Benih yang sudah berkecambah normal disapih ke dalam kantong plastik (poly bag) yang berisi media campuran pasir dan tanah (1:1). Setiap ulangan pada masing-masing ukuran benih terdiri dari 20 bibit.

Respon terhadap bibit yang diamati adalah daya berkecambah, kecepatan berkecambah, pertumbuhan tinggi, diameter bibit dan indeks mutu bibit.

Daya berkecambah ditentukan dengan jumlah benih yang sudah berkecambah normal. Menurut Sadjad (1972) Daya berkecambah menjabarkan parameter viabilitas potensial dan rumus Daya Berkecambah (DB) adalah sebagai berikut :

$$
\begin{aligned}
\mathrm{DB} & =\frac{\Sigma \mathrm{KN}}{\mathrm{N}} \mathrm{X} 100 \% \\
\Sigma \mathrm{KN} & =\text { jumlah benih yang menjadi kecambah normal sampai hari ke-60 } \\
\mathrm{N} & =\text { jumlah benih yang ditabur }
\end{aligned}
$$


Kecepatan berkecambah yang dihitung adalah benih yang berkecambah dari hari pengamatan ke-1 sampai dengan hari terakhir. Dengan penghitungan kecambah normal pada setiap pengamatan dibagi dengan etmal $(1$ etmal $=24$ jam). Menurut Sadjad (1972) Kecepatan berkecambah menjabarkan parameter vigor dan rumus kecepatan berkecambah sebagai berikut :

$$
\begin{aligned}
\mathrm{Kct} & =\underline{\mathrm{i}} \frac{\mathrm{(KN})_{\mathrm{i}}}{1} \mathrm{~W}_{\mathrm{i}} \\
\mathrm{i} & =\text { hari pengamatan } \\
\mathrm{KN} & =\text { Kecambah Normal }(\%) \\
\mathrm{W}_{\mathrm{i}} & =\text { Waktu (etmal) }
\end{aligned}
$$

Indeks mutu bibit dihitung dengan mempergunakan cara Dickson (1960) dalam Kurniaty et. al (2003):

$$
\text { Indeks mutu }=\frac{\text { Bobotkering batang }(\mathrm{g})+\text { Bobot kering akar }(\mathrm{g})}{\frac{\text { Tinggi }(\mathrm{cm})}{\text { Diameter }(\mathrm{mm})}+\frac{\text { Bobot kering batang }(\mathrm{g})}{\text { Bobot kering akar }(\mathrm{g})}}
$$

\section{Analisis data}

Data daya berkecambah, kecepatan berkecambah, pertumbuhan tinggi dan diameter bibit, dan indeks mutu bibit dianalisa menggunakan rancangan acak lengkap. Sebagai faktor perlakuan adalah ukuran benih (a0, a1, a2, dan a3). Apabila faktor-faktor tersebut berpengaruh nyata maka untuk mengetahui lebih lanjut dilakukan uji beda jarak Duncan.

\section{HASIL DAN PEMBAHASAN}

Benih mindi mempunyai kadar air bervariasi yaitu 13,47-13,64\% dengan nilai rata-rata 13,55\%. Berdasarkan hasil perhitungan diperoleh nilai rata-rata berat 1000 butir benih mindi 447,918 gram, dan banyaknya benih mindi per $1 \mathrm{~kg}$ adalah 2233 butir. Persentase hidup bibit dari benih yang berukuran besar mencapai $100 \%$, berukuran sedang $95 \%$, dan berukuran kecil $98 \%$.

1. Daya berkecambah dan kecepatan berkecambah

Hasil analisis keragaman pengaruh ukuran benih terhadap daya berkecambah dan kecepatan berkecambah (Tabel 1) menunjukkan bahwa ukuran benih tersebut berpengaruh nyata. Ini menunjukkan bahwa beberapa ukuran benih mempunyai daya berkecambah dan kecepatan berkecambah yang berbeda antara satu dengan yang lainnya. Rincian perbedaan lebih lanjut ditelaah dengan uji beda jarak Duncan (Tabel2). 
Tabel (Table) 1. Rekapitulasi analisa keragaman daya berkecambah, kecepatan berkecambah, tinggi bibit, diameter bibit dan indeks mutu bibit benih mindi berdasarkan ukuran benih (Recapitulation of analisys of variance on germination percentage, germination rate, seedling height, seedling diameter, and seed quality index of mindi seeds based on seed size)

\begin{tabular}{|c|c|c|c|c|c|}
\hline $\begin{array}{l}\text { Sumber Keragaman } \\
\text { (Sources of } \\
\text { variation) }\end{array}$ & $\begin{array}{l}\text { Derajat Bebas } \\
\text { (Degrees of } \\
\text { freedom) }\end{array}$ & $\begin{array}{l}\text { Jumlah } \\
\text { Kuadrat } \\
\text { (Sums of } \\
\text { Square) }\end{array}$ & $\begin{array}{l}\text { Kuadrat } \\
\text { Tengah (Mean } \\
\text { square) }\end{array}$ & $\begin{array}{c}\text { F hitung } \\
(F \text {-cale })\end{array}$ & $\begin{array}{l}\mathrm{F} \text { tabel } \\
(F \text {-table })\end{array}$ \\
\hline $\begin{array}{l}\text { Daya Berkecambah } \\
\text { (Germination } \\
\text { percentage) } \\
\text { Sisa (Error) } \\
\text { Total }\end{array}$ & $\begin{array}{l}3 \\
8 \\
11\end{array}$ & $\begin{array}{l}3082,917 \\
123,333 \\
3206,250\end{array}$ & $\begin{array}{l}1027,639 \\
15,417\end{array}$ & $66,66 *$ & 4,07 \\
\hline $\begin{array}{l}\text { Kecepatan } \\
\text { Berkecambah } \\
\text { (Germination rate) } \\
\text { Sisa (Error) } \\
\text { Total } \\
\end{array}$ & $\begin{array}{l}3 \\
8 \\
11 \\
\end{array}$ & $\begin{array}{l}8,050 \\
1,150 \\
9,200 \\
\end{array}$ & $\begin{array}{l}2,683 \\
0,144\end{array}$ & $18,669 *$ & 4,07 \\
\hline $\begin{array}{l}\text { Tinggi bibit } \\
\text { (Seedling height) } \\
\text { Sisa (Error) } \\
\text { Total }\end{array}$ & $\begin{array}{l}3 \\
229 \\
232\end{array}$ & $\begin{array}{l}106,311 \\
1397,193 \\
1503,504\end{array}$ & $\begin{array}{l}35,437 \\
6,101\end{array}$ & $5,808 *$ & 3,88 \\
\hline $\begin{array}{l}\text { Diameter bibit } \\
\text { (Seedling diameter) } \\
\text { Sisa (Error) } \\
\text { Total }\end{array}$ & $\begin{array}{l}3 \\
229 \\
232\end{array}$ & $\begin{array}{l}22,373 \\
31,149 \\
53,521\end{array}$ & $\begin{array}{l}7,458 \\
0,136\end{array}$ & $54,827 *$ & 3,88 \\
\hline $\begin{array}{l}\text { Indeks mutu bibit } \\
\text { (seed quality index) } \\
\text { Ukuran benih } \\
\text { (Seed size) } \\
\text { Sisa (Error) } \\
\text { Total }\end{array}$ & $\begin{array}{l}3 \\
56 \\
59\end{array}$ & $\begin{array}{l}0,005 \\
0,036 \\
0,041\end{array}$ & $\begin{array}{l}0,002 \\
0,001\end{array}$ & $2,59 \mathrm{~ns}$ & 2,78 \\
\hline
\end{tabular}

Keterangan (Remark) $\mathrm{ns}=$ tidak berpengaruh nyata (not significantly different at $95 \%$ )

$* \quad=$ berpengaruh nyata $(95 \%)$ (significantly different at $95 \%)$

Dari hasil uji Duncan terlihat bahwa ukuran benih yang mempunyai daya berkecambah dan kecepatan berkecambah terbesar adalah benih yang berukuran besar kemudian diikuti oleh ukuran sedang dan kecil. Daya berkecambah benih mindi yang berukuran kontrol $(70,33 \%)$ dan besar $(73 \%)$ lebih tinggi daripada benih berukuran sedang dan kecil (Tabel 2). Selanjutnya benih berukuran besar $(3,7193 \% \mathrm{KN} /$ et mal) memiliki kecepatan berkecambah tertinggi, diikuti oleh benih kontrol $(3,5814 \% \mathrm{KN} /$ et mal), sedang $(2,9580 \% \mathrm{KN} / \mathrm{etmal})$, dan kecil (1,6478\% KN/etmal) (Tabel 2). Hal ini menunjukkan benih mindi sejalan dengan teori yang menyatakan benih yang berukuran besar cenderung memiliki viabilitas yang lebih baik dan berkecambah lebih cepat (Schmidt, 2002). Hal tersebut mungkin terjadi karena ukuran embrio dan cadangan makanan yang lebih besar. Benih yang berukuran besar berindikasi memiliki lebih banyak cadangan makanannya dibanding yang berukuran sedang dan kecil, dengan cadangan makanan yang lebih banyak tersebut maka benih berukuran besar mempunyai daya berkecambah dan kecepatan berkecambah yang lebih besar dan cepat dibandingkan ukuran lain. 
Tabel(Table) 2. Rata-rata daya berkecambah dan kecepatan berkecambah benih mindi dari berbagai ukuran berdasarkan uji Duncan (Average of germination percentage and germination rate over various seed size based on Duncan's test)

\begin{tabular}{|l|l|l|}
\hline $\begin{array}{l}\text { Ukuran Benih } \\
\text { (Seed Size) }\end{array}$ & $\begin{array}{c}|c| \\
\text { Daya berkecambah } \\
\text { (Germination percentage) }(\%)\end{array}$ & $\begin{array}{c}\text { Kecepatan berkecambah } \\
\text { (Germination rate) }(\% \text { KN/et mal) }\end{array}$ \\
\hline Kontrol (control) & 70,33 a & 3,5814 ab \\
\hline Besar (big) & $73,00 \mathrm{a}$ & $3,7193 \mathrm{a}$ \\
\hline Sedang (medium) & $55,00 \mathrm{~b}$ & $2,9580 \mathrm{~b}$ \\
\hline Kecil (small) & $32,67 \mathrm{c}$ & $1,6478 \quad \mathrm{c}$ \\
\hline
\end{tabular}

Keterangan (Remark): Angka yang diikuti huruf yang berbeda menunjukkan adanya perbedaan pada tingkat kepercayaan 95\% (Figure followed with the same letters are not significantly different at $95 \%$ level $): \mathrm{a}>\mathrm{b}>\mathrm{c}$

\section{Pertumbuhan Tinggi dan Diameter Bibit}

Untuk melihat pengaruh ukuran benih mindi terhadap pertumbuhan tinggi dan diameter bibitnya dilakukan analisis sidik ragam ( Tabel 1) ukuran benih berpengaruh nyata terhadap pertumbuhan tinggi dan diameter bibit. Untuk melihat ukuran benih mana yang berpengaruh dilakukan uji beda jarak Duncan (Tabel 3).

Tabel (Table) 3. Rata-rata tinggi dan diameter bibit mindi dari masing-masing ukuran benih berdasarkan uji Duncan (Average height and diameter of mindi seeds from various seed size based on Duncan's test)

\begin{tabular}{|l|l|l|}
\hline $\begin{array}{l}\text { Ukuran Benih } \\
\text { (Seed Size) }\end{array}$ & \multicolumn{1}{|c|}{$\begin{array}{c}\text { Tinggi bibit } \\
\text { (Seedling height) }\end{array}$} & $\begin{array}{c}\text { Diameter bibit } \\
\text { (Seedling diameter) }\end{array}$ \\
\hline Kontrol (control) & $12,88 \mathrm{~b}$ & $1,08 \mathrm{c}$ \\
\hline Besar (big) & $12,55 \mathrm{~b}$ & $1,84 \mathrm{a}$ \\
\hline Sedang (medium) & $13,98 \mathrm{a}$ & $1,84 \mathrm{a}$ \\
\hline Kecil (small) & $12,16 \mathrm{~b}$ & $1,51 \mathrm{~b}$ \\
\hline
\end{tabular}

Keterangan(Remarks): Angka yang diikuti huruf yang berbeda menunjukkan adanya perbedaan pada tingkat kepercayaan $95 \%$ (Figure followed with the same letters are not significantly different at $95 \%$ level $): \mathrm{a}>\mathrm{b}>\mathrm{c}$

Dari Tabel 3 dapat dilihat bahwa tinggi bibit tertinggi berasal dari benih ukuran sedang. Sedangkan tinggi bibit yang lebih rendah berasal dari benih kontrol, benih ukuran besar dan kecil, dimana tinggi bibit asal benih dengan 3 macam ukuran tidak saling berbeda nyata. Dalam hal diameter bibit, diameter terbesar adalah benih berukuran besar dan sedang, diikuti oleh diameter bibit ukuran kecil dan kontrol.

Hal ini mengindikasikan bahwa benih mindi berukuran sedang hingga besar (panjang $\geq 11 \mathrm{~mm}$ dan diameter $\geq 6,5 \mathrm{~mm}$ ) dapat dipergunakan sebagai acuan untuk proses seleksi benih untuk menghasilkan bibit siap tanam yang vigor di lapangan. Benih mindi berukuran sedang dan besar dengan penampilan bibitnya dapat menghemat biaya pemeliharaan di persemaian dan dapat mengejar target penyiapan bibit untuk menghadapi waktu penanaman, mengingat waktu tersebut sangat penting bagi pengelolaan persemaian (Wadsworth, 1997).

Benih mindi berukuran sedang walaupun secara nyata berpengaruh terhadap tinggi bibit dengan nilai rata-rata terbesar $(13,98 \mathrm{~cm})$ dan berbeda nyata dengan ukuran benih yang lain, tetapi untuk diameter bibit, tidak berbeda nyata dengan ukuran benih besar dengan nilai rata-rata $1,84 \mathrm{~mm}$, tetapi berbeda nyata dengan ukuran benih lainnya. 

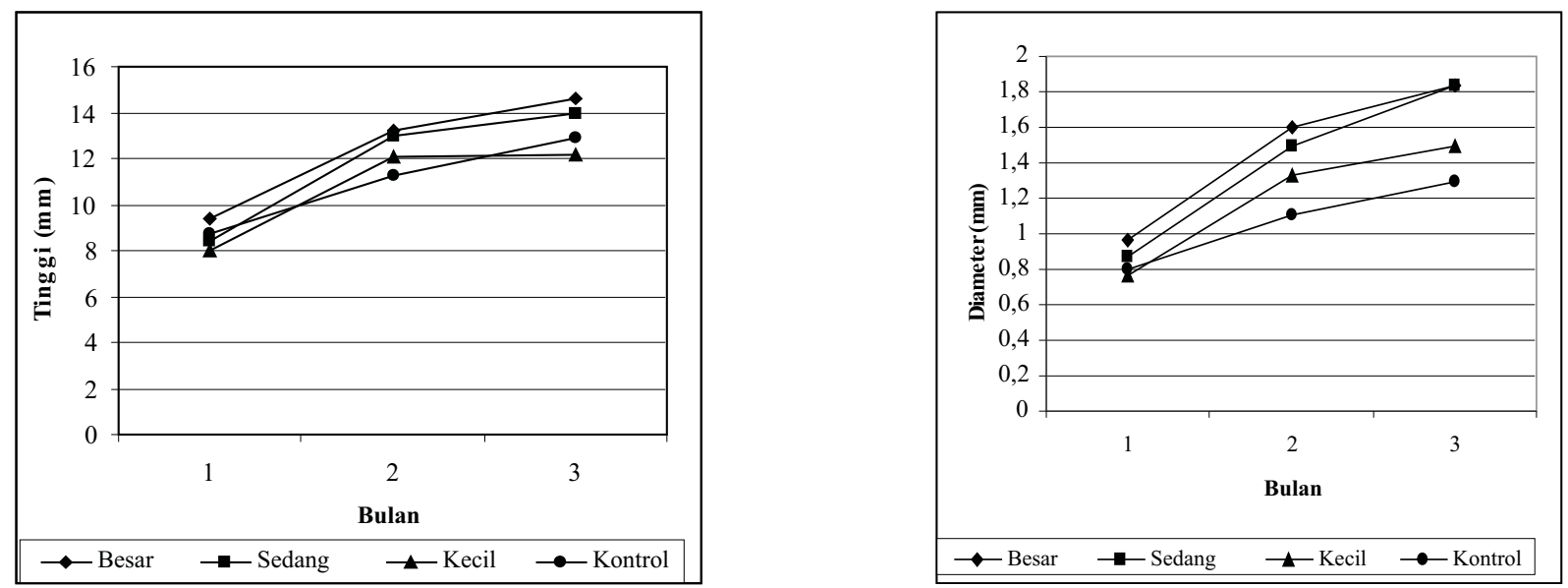

Gambar(Figure) 1. Perkembangan tinggi dan diameter total bibit tanaman dari berbagai ukuran benih mindi (Growth in height and diameter of mindi seeds at various seed size)

Pada Gambar 1 terlihat bahwa peningkatan pertambahan rata-rata tinggi bibit mindi sejalan dengan pertambahan umur bibit pada pengukuran 1 bulan sampai 3 bulan. Benih mindi berukuran sedang hingga besar dilihat dari pertumbuhan tinggi dan diameter bibit lebih baik dari ukuran benih lainnya sehingga mempunyai prospek untuk dipergunakan dalam pengadaan bibit di lapangan. Benih mindi berukuran besar ( panjang $>14 \mathrm{~mm}$ dan diameter $>8,5 \mathrm{~mm}$ ) menghasilkan pertumbuhan tinggi bibit tertinggi 13,98 cm dan berbeda dengan ukuran benih lainnya, sedangkan diameter benih berukuran besar dan sedang ( panjang 11- $14 \mathrm{~mm}$ dan diameter 6,5-8,5 mm) mencapai nilai tertinggi 1,84 $\mathrm{mm}$ yang berbeda dengan ukuran benih lainnya. Hal ini disebabkan kecepatan berkecambah pada kedua ukuran ini (besar dan sedang) lebih tinggi dibandingkan dengan benih berukuran kecil, sehingga energi pertumbuhan ini masih berlangsung sampai pertumbuhan tinggi bibit. Dengan demikian, benih mindi berukuran sedang hingga besar memiliki potensi yang untuk mendukung perkembangan bibit ke arah siap tanam, dengan parameter tinggi dan diameter sebagai salah satu kriteria morfologi bibit, selain penampakan daun, batang dan bentuk tunas, bentuk dan volume akar, dan potensi pertumbuhan akar (Hawkins, 1996).

\section{Indeks Mutu Bibit}

Hasil analisa keragaman pengaruh ukuran benih mindi terhadap indeks mutu bibit (Tabel 1), ukuran benih tidak berpengaruh nyata. Indeks mutu bibit diukur pada saat bibit berumur 3 bulan dan mempunyai tinggi masih di bawah $15 \mathrm{~cm}$. Walaupun secara statistik indeks mutu tidak ada perbedaan yang nyata, tetapi dari rata-rata nilai indeks mutu, nilai yang tertinggi diperoleh dari bibit yang berasal dari benih berukuran sedang $(0,0433)$ kemudian diikuti dengan yang berukuran besar $(0,0407)$ dan kecil $(0,0367)$.

Pengumpulan benih tanjung selain dilakukan hanya terhadap benih yang bernas, yaitu hanya benih-benih yang viabel, tidak tercampur dengan benih kosong, busuk atau benih-benih yang mengalami kerusakan fisik seperti pecah, retak dan kondisi benih lainnya yang mengalami kerusakan struktur benih, juga memperhatikan ukuran benih. Dalam penelitian ini ukuran benih yang direkomendasikan dalam pengumpulan benih mindi adalah yang berukuran besar dan sedang (panjang $\geq 11 \mathrm{~mm}$ dan diameter $\geq 6,5 \mathrm{~mm}$ ) tetapi cara seleksi sebaiknya bersifat praktis karena perbedaan ukuran benih dalam jenis yang sama tidak terlalu besar, dibandingkan dengan jenis yang berbeda. Tetapi seleksi benih yang dilakukan juga harus memperhitungkan implikasi mutu genetik benih seperti hilangnya komposisi benih lainnya yang kemungkinan secara genetik lebih baik (Schmidt, 2002). 


\section{KESIMPULAN}

Daya berkecambah benih tanpa perlakuan (kontrol) mempunyai daya berkecambah sebesar $70,33 \%$ dan benih besar (73.00 \%) lebih baik dan berbeda nyata dibandingkan dengan ukuran sedang $(55,00 \%)$ dan kecil $(32,67 \%)$, dengan demikian semakin besar ukuran benih maka semakin tinggi daya berkecambahnya. Kecepatan berkecambah benih berukuran besar $(3,7193 \% \mathrm{KN} /$ etmal) memiliki kecepatan berkecambah tertinggi, tidak berbeda nyata dengan benih kontrol $(3,5814 \% \mathrm{KN} / \mathrm{et} \mathrm{mal})$, dan berbeda nyata dengan berukuran sedang $(2,9580 \% \mathrm{KN} /$ etmal), dan kecil (1,6478 \% KN/etmal). Ukuran benih sedang memiliki pertumbuhan tinggi bibit terbesar $(13,98 \mathrm{~cm})$ dan berbeda nyata dengan lainnya, tetapi untuk pertumbuhan diameter, ukuran benih sedang dan besar memiliki nilai yang sama $(1,84 \mathrm{~mm})$ dan berbeda nyata dengan ukuran benih lainnya. Dari penelitian ini disarankan seleksi benih untuk mindi sebaiknya didasarkan pada ukuran benih sedang dan besar, dengan tetap memperhatikan benih hampa dan terkena serangan hama dan penyakit.

\section{DAFTAR PUSTAKA}

Anonim. 1999. Seed Science and Technology. International Seed Testing Assosiation (ISTA). Switzerland.

Bonner, F.T. 1987. Importance of Seed Size in Germination and Seedling Growth. Southern Forest Experiment Station. USDA. New Orleans, Louisiana.

Chaisurisri, K., D.G.W. Edward, and Y.A. El-Kassaby. 1994. Effect on Seed Size on Seedling Attributes in Sitka Spruce. New Forest, 8: 8, 81-87.

Hawkins, B.J. 1996. Planting Stock Quality Assessment. In Yapa, A.C., ed. 1996. Proc. Intl. Symp. Recent advances in tropical tree seed technol. and Planting stock production. ASEAN Forest Tree Seed Centre, Muaklek, Saraburi, Thailand.

Hendromono. 1996. Pengaruh Ukuran Benih terhadap Persen Jadi dan Pertumbuhan Bibit Hymenaea coubaril L. Buletin teknologi Perbenihan. Vol. 3 No. 2. Badan Penelitian dan Pengembangan Kehutanan dan Perkebunan. Balai Teknologi Perbenihan. Bogor.

Kurniaty, R. dan Y. Heryati. 2003. Pengaruh Intensitas Cahaya dan Pemupukan terhadap Pertumbuhan Bibit Cempaka Hutan (Ermerillia ovalis). Buletin Teknologi Perbenihan. Vol. 10 No. 2. Badan Penelitian dan Pengembangan Kehutanan. Pusat Penelitian dan Pengembangan Bioteknologi dan Pemuliaan Tanaman Hutan. Bogor

Martawijaya, A., Kartasujana, I., Mandang, Y.I., Prawira, S.A. dan Kadir, K. 1989. Atlas Kayu Indonesia Jilid II. Badan Litbang Kehutanan, Departemen kehutanan. Bogor.

Schmidt, L. 2002. Pedoman Penanganan Benih Tanaman Hutan Tropis dan Sub Tropis. Direktorat Jenderal Rehabilitasi Lahan dan Perhutanan Sosial Indonesia Forest Seed Project. PT. Gramedia. Jakarta. (terjemahan).

Sorensen, F.C. and Campbell, R.K. 1993. Seed Weight-Seedling Size Correlation in Coastal Douglas Fir: Genetic and Environmental Component. Canadian Jurnal of Forest Research. 23:2, 275-285.

Wadsworth, F.H. 1997. Forest Production for Tropical America. USDA Forest Service. Agriculture Handbook 710. Rio Piedras. USA. 